\title{
A case study of rare lympho-epithelioma like esophageal carcinoma
}

\author{
Abhishek Mukherjee ${ }^{1}$, Jaydeep Nath ${ }^{1}$, Srimanti Sinha ${ }^{1}$ and Tridip Chatterjee ${ }^{2 *}$ \\ ${ }^{1}$ Suraksha Diagnostic Centre, Salt Lake, Kolkata, West Bengal, India \\ ${ }^{2}$ Suraksha Genomics (R\&D Division of Suraksha Diagnostic), Salt Lake, Kolkata, West Bengal, India
}

\begin{abstract}
Sub classification of esophageal carcinoma is important due to differences in prognosis and management. Esophageal Lymphoepithelioma-Like Carcinoma (LELC) is extremely rare, with only a few cases reported to date. Carcinoma with lymphoid infiltration in the stomach, breast or nasopharynx has a good prognosis, but in the esophagus this histological type is extremely rare and its characterization is unclear.
\end{abstract}

Review of the literature revealed case reports describing lesions with similar histology. We present a 69-year-old man with a giant pedunculated-polypoid lesion of the esophagus shrinking the lumen. Endoscopic excision of the tumor was performed and final histopathological diagnosis was confirmed to be LELC.

\section{Introduction}

Lymphoepithelioma-like Carcinoma (LELC) can be defined as a tumor with histological similarity to undifferentiated nasopharyngeal carcinoma, which has lymphoid stroma (lymphoepithelioma) that occurs outside the nasopharynx. LELC has been usually detected in organs like the thymic gland [1], breast [2], stomach [3], salivary gland [4] and lungs [5]. But, tumors of the esophagus other than squamous cell carcinoma and adenocarcinoma are quite rare [6]. The prognosis of patients suffering from this type of cancer has been reported to be favorable [7]. Lymphoepithelioma-like carcinoma (LELC) has been described as an un- or poorly-differentiated form of squamous cell carcinoma associated with reactive lymphoplasmacytic infiltration. The stomach is the most common site for gastrointestinal LELC; however, esophageal involvement is occasionally observed [8]. In the stomach and breast, undifferentiated medullary carcinoma with lymphoid infiltration has been shown to have a good prognosis [9]. Esophageal LELC are primarily submucosal lesions with normal-appearing epithelial coverage and rarely can have polypoid, ulcerative, or reddish mucosal irregularity [8]. The prognosis of patients suffering from this type of cancer has been reported to be favorable [10].

\section{Case report}

The patient was a 69-year-old man presented with weight loss, loss of appetite, and dysphagia. Routine blood laboratory test results indicated no abnormality. Thoracic computed tomography (CT) examination with intravenous contrast agent injection revealed a nodular, esophageal soft tissue mass at the level of the carina. The size of the lesion was $13 \times 10 \mathrm{~mm}$ axially . Paratracheal, subcarinal, and bilateral hilar lymphadenopathies were detected in the mediastinal region. Upper endoscopy revealed a giant pedunculated-polypoid lesion partially shrinking the esophageal lumen at $23 \mathrm{~cm}$ from the incisor. Yellowish-white exudative secretion over the polypoid lesion was present. The esophageal mucosa was irregular; reddish colored, and contained erosion from the level of the lesion to the cardioesophageal junction.
Endoscopic guided biopsy was performed and tissue material sent in $10 \%$ buffered formalin for histological opinion. Histologically, the large-sized carcinoma cells formed small focal nests and infiltrated into the submucosal layer. Prominent infiltration of T lymphoid cells, was observed between and around the carcinoma cells. Based on these histopathological features, this lesion was considered to be an LELC with poorly differentiated squamous cells. The patient's complaint of dysphagia ended immediately after polypectomy.

\section{Methodologies}

Endoscopic guided biopsy was received in Histopathology Department. Multiple tissue fragments procured went through routine tissue processing on automated tissue processor and $\mathrm{H} \& \mathrm{E}$ staining was performed for microscopic examination (Figures 1-3).

\section{Discussion}

LELC was first reported by Bégin et al. in 1987 [10]. LELC is defined as a tumor with histological similarity to undifferentiated nasopharyngeal carcinoma with lymphoid stroma, and this condition has been described in various organs. However, an esophageal LELC is extremely rare. Burke first detected EBV DNA in gastric cancer that histologically resembled nasopharyngeal lymphoepithelioma and after that several reports also demonstrated a close relationship between that type of gastric cancer and EBV. However, there does not appear to be a relationship between esophageal cancer and EBV [10].

LELC tumors can arise in a multitude of locations such as the thyroid and breast, as well as gastrointestinal sites such as the biliary

Correspondence to: Tridip Chatterjee, Suraksha Genomics (R \& D Division of Suraksha Diagnostic) DD-18/1. Sector 1, Salt Lake, Kolkata-700064, West Bengal, India, Tel: 9198313252580 E-mail: ctridip@gmail.com, tridip.academic@gmail.com

Received: January 05, 2017; Accepted: January 24, 2017; Published: January 27, 2017 

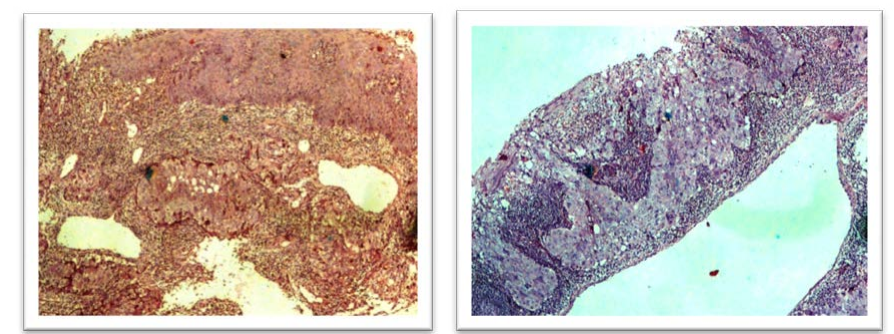

Figure 1. Histopathologic examination of the lesion. The tumor is characterized by syncytial nests and sheets of undifferentiated cells (H\&E stain, $\times 40)$.

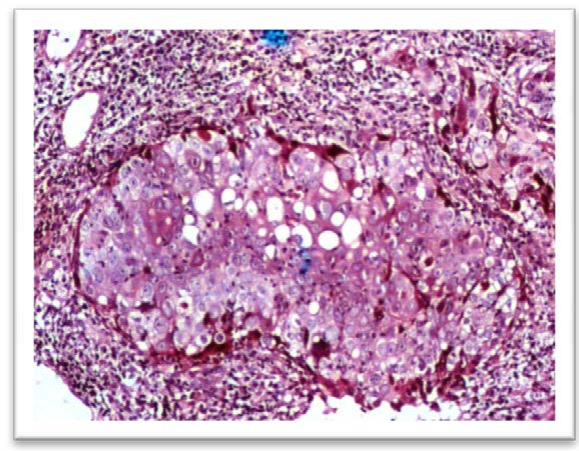

Figure 2. Histopathologic examination of the lesion. The tumor is characterized by nests of undifferentiated cells with large nuclei and poorly defined cytoplasmic borders (H\&E stain $\times 100)$.

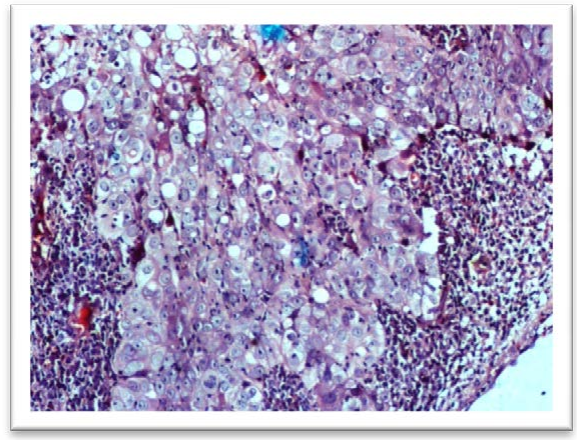

Figure 3. The histopathological findings.Nests of poorly differentiated squamous cells and lymphocytes that had infiltrated into the carcinoma cell nests were observed (HE staining $\times 400)$.

system, stomach, and colon. While the histologic features are similar, clinical presentation, age, sex, stage at presentation, size, and overall survival vary dramatically between sites. LELC has a better prognosis compared to conventional gastrointestinal adenocarcinoma [9].
The most characteristic endoscopic appearance of esophageal LELC is submucosal tumor covered with intact or ulcerative esophageal mucosa and a depressed middle portion. Exceptional cases may have simple ulcerative morphology, polypoid lesion, or solely reddish mucosal irregularity in our case, the lesion was polypoid and the accompanying reddish mucosal irregularity was established from the lesion to the level of the cardioesophageal junction [10]. The role of diffuse infiltrating lymphocytes, consisting of a large number of $\mathrm{T}$ lymphocytes and a small number of B lymphocytes, has not yet been clarified in LELC. Two hypotheses have been proposed. In one, the presence of diffuse lymphocytes is explained by the immune response of the host against the carcinoma. In the other, the diffuse lymphocytes are explained in terms of a cell reaction caused by the cytokines produced by the carcinoma cells.

Generally, the prognosis of patients suffering from poorly differentiated esophageal squamous cell carcinoma is extremely poor. However, esophageal LELC seems to have a relatively good prognosis [7]. The prognosis is indicated by the survival curves and recurrence rates after treatments [10].

\section{References}

1. Leyvraz S, Henle W, Chahinian AP, Perlmann C, Klein G, et al. (1985) Association of Epstein-Barr virus with thymic carcinoma. N Engl J Med 312: 1296-1299. [Crossref]

2. Moore OS Jr, Foote FW Jr (1949) The relatively favorable prognosis of medullary carcinoma of the breast. Cancer 2: 635-642. [Crossref]

3. Watanabe H, Enjoji M, Imai T (1976) Gastric carcinoma with lymphoid stroma. Its morphologic characteristics and prognostic correlations. Cancer 38: 232-243

4. Saemundsen AK, Albeck H, Hansen JP, Nielsen NH, Anvret M, et al. (1982) EpsteinBarr virus in nasopharyngeal and salivary gland carcinomas of Greenland Eskimoes. $\mathrm{Br}$ $J$ Cancer 46: 721-728. [Crossref]

5. Butler AE, Colby TV, Weiss L, Lombard C (1989) Lymphoepithelioma-like carcinoma of the lung. Am J Surg Pathol 13: 632-639. [Crossref]

6. Sashiyama H, Nozawa A, Kimura M, Nomura E, Tamaru JI, et al. (1999) Case report: A case of lymphoepithelioma-like carcinoma of the oesophagus and review of the literature. J Gastroenterol Hepatol 14: 534-539. [Crossref]

7. Gaffey MJ, Weiss LM (1992) Association of Epstein-Barr virus with human neoplasia. Pathol Annu 27 Pt 1: 55-74. [Crossref]

8. Olmez S, Can A, Yavuz A, Ä ${ }^{\circ}$ liklerden UH, Bulut G (2015) Esophageal Lymphoepithelioma-Like Carcinoma with Unique Daisy-Like Appearance. Clin Endosc 48: 549-552. [Crossref]

9. Masaya Uesato, Tuguaki Kono, Tooru Shiratori, Yasunori Akutsu et al. (2014) Lymphoepithelioma-like esophageal carcinoma with macroscopic reduction. World $J$ Gastrointest Endosc 6: 385-389.

10. Katsuhiko Shimizu, Wataru Takiyama, Koichi Mandai et al. (1999) Undifferentiated Carcinoma with Lymphoid Infiltration of the Esophagus: A Case Report. Jpn J Clin Oncol 29: 494-497.

Copyright: (C2017 Mukherjee A. This is an open-access article distributed under the terms of the Creative Commons Attribution License, which permits unrestricted use, distribution, and reproduction in any medium, provided the original author and source are credited. 